\title{
Estimating the enzyme specificity and glucose concentration of sugar solutions
}

\section{Rishan Singh}

University of KwaZulu-Natal. Durban, 4001, South Africa. Email: rshnsingh1@webmail.co.za.

\begin{abstract}
The function of the human body are controlled by enzymes and hormones. Similarly, in the laboratory, the enzyme, glucose oxidase, is used to hydrolyse glucose. In the human body, glucose and insulin control blood glucose levels, which are dependent on food intake. In this study, the enzyme specificity and glucose concentration of sugar solutions would be estimated. In order to achieve this, an experiment involving the use of indicator strips and a two-fold serial dilution was performed. Furthermore, conclusions on blood glucose and serum insulin levels would also be discussed from a given data set.
\end{abstract}

Keywords: Enzyme; Reactants products; Potassium iodide; Energy supplement; Food intake; Hormones; Pancreas.

\section{Introduction}

Enzyme specificity refers to the selectivity of an enzyme to a specific substrate. The substrate can be anything, usually a substrate or substance, on which the enzyme is able to initiate a chemical reaction (Singh, 2019). The chemical reaction that occurs results in the formation of products, and the substance on which the enzyme acts, is the substance. Enzymes act on substrate in wither a lock-and-key theory of enzyme action or through chemical modification (Becker et al., 2003). In the lock and key theory, the enzyme forms a lock-and-key theory configuration with the substrate, and if the conditions are favourable, the reaction proceeds to completion. This is called a first order reaction. The chemical modification reaction is also a first order reaction, however, it doesn't go to completion if the reactants are not chemically compatible (Matthews et al., 2000). This means that the substrate has to be chemically similar to the enzyme for the reaction to reach completion (Singh, 
2019). For example, maltose can't act on fructose since the monomers in fructose are different compared to maltose. However, through chemical modification of fructose, it may be possible to catalyse some hydrolysis of maltose to glucose. In this situation, very little or no fructose will be converted to glucose. Therefore, it must be noted that enzyme specificity if also related to reaction temperature and $\mathrm{pH}$ conditions, and that the substrate configuration, viz. glucose, must be compatible for the enzyme to hydrolyse it (Singh, 2019).

\section{Materials and methods}

In order to estimate the enzyme specificity and glucose concentration of major solutions, a glucose detection system was made. The enzymes, glucoseoxidase and peroxidase are immobilised on a paper pad at the end of a detection strip. The pad is made selectively permeable by covering it with a cellulose membrane. This allows for selective permeability so that glucose molecules can be detected. The products react with oxygen and water to produce a colour change, and the glucose concentration of a sugar solutions can be estimated quantitatively by assessing the intensity of the colour change.

\section{Enzyme specificity estimation}

Four strips of filter paper were labelled to the sugar solution to be tested. There were three sugar solutions that were tested. These were sucrose, fructose and glucose. One drop of the solution to be tested was added to one strip and left to dry for $5 \mathrm{~min}$. The control strip received one drop of deionised water and no sugar solution was added. Thereafter one drop of the enzyme was added to the area of the sugar solution, and left to react for $5 \mathrm{~min}$. Then, one drop of potassium iodide was added to the reacting area of the filter paper. The strips were observed for a colour change between 10-15 min. from the time indicator, potassium iodide, had been added (BIOL 103 Practical Manual, 2019).

\section{tion \\ Glucose concentration estima- \\ A $10 \%$ glucose solution was used} to estimate the glucose concentration. 6 test tubes were arranged in a rack and labelled as $10 \%$ (1), $5 \%$ (2), $2.5 \%$ (3), $1.25 \%$ (4), $0.625 \%$ (5) and the control (6). $5 \mathrm{~mL}$ deionised water was dispended into all tubes from number 2 to 6 . In the first tube, $10 \mathrm{~mL}$ of $10 \%$ glucose solution was added. Then from tube 1, $5 \mathrm{~mL}$ was removed and added into tube 2 . The solution was mixed gently. This procedure was carried out from tube 2 to 5 , so that a two-fold dilution was achieved. No glucose solution was added to the control tube. From tubes 1 to 5 , there was a $50 \%$ gradual decrease in initial glucose concentration. After this was done, 6 strips of filter paper was labelled for each tube, and the experiment for enzyme specificity (described in $a$ ) was performed. After 15 min, the colour change observation were recorded. In order to confirm the results of the glucose and enzyme specificity test, a $4 \%$ glucose solution was tested. In addition, Energade, a sport drink, and super C sweet (dissolved in $50 \mathrm{~mL}$ deionised water was tested (BIOL 103 Practical Manual, 2019).

\section{Blood glucose and insulin}

The relationship of blood glucose and insulin levels in the bloodstream of a person was analysed from a given data set. The reading from a person's blood over a $12 \mathrm{~h}$ period was analysed (BIOL 103 Practical Manual, 2019).

\section{Results and discussion}

The results of the enzyme specificity and glucose concentration experiments show that glucose oxidase is specific for glucose, and that it doesn't catalyse fructose and sucrose to gluconic acid. The visible brown colour was obtained for the glucose solution only 
since hydrogen peroxide is also produced during hydrolysis of glucose in the presence of water and oxygen, by glucose oxidase. The peroxidase enzyme only yield a brown colour if hydrogen peroxide is produced. This was only produced in the reaction with glucose. The latter reaction yields iodine, the brown colour and water. For the indicator strip experiment, it was found that there was a graded decrease in the intensity of the brown colour. From tubes 1 to 5 , since the enzyme hydrogen peroxidase and the indicator, potassium iodide is dependent on the concentration of the glucose. This was the case since only the glucose concentration varied in each test tube. This result was considered optimum and it was consistent with the $4 \%$ glucose solution that was also tested. Therefore, the results of the $10 \%$ glucose solution is conclusive and in keeping with other studies (read Hans et al., 2006; and Wright et al., 2000). In the experiment with the unknown, namely Energade and super $\mathrm{C}$, it was found that approximately $2.8 \%$ of glucose was present in Energade, while only $0.165 \mathrm{~g}$ was present in super C. The latter reading was taken to be an experimental error, since super $C$ is an energy supplement. Furthermore, one would expect a higher glucose concentration to be obtained for super C. The $2.8 \mathrm{~g}$ was extrapolated to one of the tested indicator strips for the serial dilutions. The colour of the strips matched an approximate reading for Energade, i.e. 2.8 g. The table below shows the results of a patient's blood glucose and serum insulin over a $12 \mathrm{~h}$ period.

Table 1. Levels of glucose and insulin in patients' blood and serum over $12 \mathrm{~h}$.

\begin{tabular}{|l|c|c|}
\hline Time/Hour & Blood glucose (mmol/L) & Serum insulin (pmol/L) \\
\hline 0 & 8 & 250 \\
\hline 1 & 7.5 & 270 \\
\hline 2 & 6 & 200 \\
\hline 3 & 5.5 & 180 \\
\hline 4 & 4 & 150 \\
\hline 5 & 3.8 & 100 \\
\hline 6 & 3 & 85 \\
\hline 7 & $\mathbf{2 . 8}$ & $\mathbf{5 0}$ \\
\hline 8 & $\mathbf{3}$ & $\mathbf{6 5}$ \\
\hline 9 & 6 & 120 \\
\hline 10 & 7.5 & 240 \\
\hline 11 & 6 & 180 \\
\hline 12 & 5 & 150 \\
\hline
\end{tabular}

In the Table 1 it is evident that the amount of insulin is dependent on a patient's blood glucose concentration. Glucose concentration is dependent on a person's diet and sugar intake. This means that there is a relationship between a patient's blood glucose and serum insulin levels. This relationship is evident from the sugar and insulin levels between 7 and $8 \mathrm{~h}$ on the table. During this period, the person may have eaten something sweet for there to be a fluctuation in the sugar and insulin secretory levels. It is evident from Table 1, that the amount of blood insulin secreted is directly proportional to the amount of glucose in the blood. For example at $5<\mathrm{mmol} / \mathrm{L}$ glucose there was $180 \mathrm{pmol} / \mathrm{L}$ insulin secreted. Similarly, at $12 \mathrm{~h}$, the patient has an 
insulin blood secretion of $150 \mathrm{pml} / \mathrm{L}$ with a blood glucose level of 5 ( $\mathrm{mmol} / \mathrm{L})$. This is the case since the pancreas controls blood sugar levels. When the blood glucose levels are low, e.g. when one skips a meal or does exercise, less insulin is secreted to raise the blood glucose levels. During this period, glucagon is secreted and this hormone has an effect on the lever. When the glucose level is high, the beta cells of the pancreas are stimulated to release insulin. This serves to decrease the concentration of glucagon in the blood.

In this study, it is evident that estimating enzyme specificity and glucose concentration is dependent on glucose concentration. Furthermore, in the human body, sugar concentration is dependent on the amount of glucagon and insulin secreted in response to food intake or dietary deficiency.

\section{Conflicts of interest}

Authors declare that they have no conflict of interests.

\section{References}

Becker, Wayne M.; Deamer, David W. The world of the cell. San Francisco: Pearson Education, 2003. (Benjamin/Cummings Series in the Life Sciences).

BIOL 103 Practical Manual. Introductory Biology for the Health Sciences. School of Life Sciences, UKZN, Westville, 2019.
Hans, P.; Vanthuyne, A.; Dewandre, P. Y.; Brichant, J. F.; Bonhomme, V. Blood glucose concentration profile after $10 \mathrm{mg}$ dexamethasone in non-diabetic and type 2 diabetic patients undergoing abdominal surgery. BJA: British Journal of Anaesthesia, v. 97, no. 2, p. 164-170, 2006. https://doi.org/10.1093/bja/ael111

Matthews, C. K.; van Holde, K. E.; Ahern, K. G. Biochemistry. San Franscisco: Addison Wesley Longman, 2000.

Singh, R. Personal writing and communication. Representing the Republic of South Africa, 2019.

Wright, T. E.; Martin, D.; Qualls, C.; Curet, L. B. Effects of intrapartum administration of invert sugar and D5LR on neonatal blood glucose levels. Journal of Perinatology, v. 20, no. $4, \quad$ p. $217-218,2000$. https://doi.org/10.1038/sj.jp.7200366 